\title{
Biomarkers of Temporomandibular Disorders
}

\author{
Sumantri DDS $S^{1,2}$, Naliani $S^{1,3}$, Lelyana $S^{1,4}$, Sandra $F^{1,5}$ \\ ${ }^{1}$ Postgraduate Program of Dental Science, Faculty of Dentistry, Universitas Trisakti \\ ${ }^{2}$ Department of Dentomaxillofacial Radiology, Faculty of Dentistry, Maranatha Christian University \\ ${ }^{3}$ Department of Prosthodontics, Faculty of Dentistry, Maranatha Christian University \\ ${ }^{4}$ Department of Oral Medicine, Faculty of Dentistry, Maranatha Christian University \\ ${ }^{5}$ Department of Biochemistry and Molecular Biology, Faculty of Dentistry, Universitas Trisakti
}

\begin{abstract}
Temporomandibular disorder is a disorder that includes masticatory muscles or temporomandibular joints, unbalanced joint function or both. The disorders can disturb daily activity, cause by pain. The therapy consuming time and cost. Early detection of temporomandibular disorder is needed, as a prevention of more severe disorders. Increased cortisol can be found in myofacial pain and is not found in internal dearagement or osteoarthritis. Biomarkers of interleukin and monocyte chemoattractant proteins are only found in osteoarthritis. The use of biomarkers can be useful in detecting temporomandibular disorders. Biomarkers can be measured from blood, serum and saliva. Cortisol, dopamine and TAC are potential biomarkers in the temporomandibular disorder.
\end{abstract}

Keywords: Temporomandibular joint, biomarkers, saliva, cortisol, TAC

\section{Introduction}

Temporomandibular joint (TMJ) is a ginglimo arthrodial joint that play important role in masticatory system. TMJ is composed of glenoid fossa, articular disc and condyle. ${ }^{1}$ Temporomandibular dysfunction or disorders (TMD) includes disorders in the masticatory muscles or TMJ, impaired joint function or combination. ${ }^{2}$ According to American Academy of Orofacial Pain, TMD is a collective term that embrace a number of clinical problems involving masticatory muscles and/or associated structures such as TMJ. ${ }^{3}$ The prevalence of TMD in adolescent is $7.12 \%$ in Norway ${ }^{2}$ and $34.9 \%$ in Brazil. ${ }^{4}$ The female to male ratio is $3: 1 .^{2}$ Sign and symptom of TMD include pain around joint, earache, headache and neck ache, joint sound, functional disturbance and tinnitus. ${ }^{2-5}$

Etiology of TMD is multifactorial and includes several separate disorders. The Research Diagnostic Criteria for Temporomandibular Disease (RDC/TMD) is widely used for the diagnosis purposes. ${ }^{6}$ Diagnostic criteria of RDC/TMD comprises two classification axes. The first axis includes clinical aspect of temporomandibular disorders. This axis consist of three groups: 1 . muscle diagnosis, 2. disc displacement, 3. arthralgia, arthritis and arthrosis. The second axis in turn contemplates disabilities related to pain and psychological condition., ${ }^{2,4}$ This protocol is comprehensive, however difficult to be implemented daily due to time consuming, and so many dental and medical specialists have to be involved. ${ }^{2,5}$

The examinations of TMD are joint sound (clicking, crepitus), palpation of TMJ and associated muscles (pain), functional analysis, dental, radiographic (panoramic, transcranial, magnetic resonance imaging (MRI), computed tomography (CT), cone beam computed tomography (CBCT)) and emotional stress. ${ }^{1,2,4,8}$ Recently synovial fluid, saliva and blood can be used as the diagnostic marker for TMD. ${ }^{9,10,10-15}$ The biomarkers can also be useful to detect early TMD. 
TMJ synovial fluid can be collected from patients undergoing arthroscopy or arthrotomy surgery. ${ }^{34}$ The fluid can be aspirated from bilateral TMJ using an 18-gauge needle of a patient under nasotracheal general anesthesia. ${ }^{34,35}$ Biochemical analysis of TMJ synovial fluid shows the presence of matrix metalloproteinase-3 (MMP3) and inflammatory immunoglobulin ( $\mathrm{Ig}$ ), such as $\operatorname{IgG}, \operatorname{IgM}$ and prostaglandin; as well as elevation of tumor necrosis factor (TNF) | |, TNF| |, interleukin (IL)1 | |, IL2, IL12, IL17 and Interferon (IFN) $\alpha^{11,34,35}$

\section{BIOMARKER IN MYOFACIAL PAIN}

Two theories have dominated the research on the causes of TMD, which are psychosocial model and occlusal disharmony. ${ }^{16}$ The major factor for individuals to seek care for their TMD complaints is pain. TMD comprises a variety of complaints that are related to the masticatory system, limitation of mandibular movements and joint sounds, including pain. ${ }^{17}$ Factors such as bruxism, adverse oral habits and depression are generally believed to contribute to the development or perpetuation of the pain complaints. ${ }^{17,18}$ Therefore, pain-related factor could be a biomarker in TMD.

\section{Salivary cortisol}

Cortisol, known more formally as hydrocortisone is a steroid hormone, more specifically a glucocorticoid, produced by the zona fasciculata of the adrenal cortex. It is released in response to stress and a low level of blood glucocorticoids. Its primary functions are to increase blood sugar through gluconeogenesis; suppress the immune system; and aid in fat, protein and carbohydrate metabolism. It also decreases bone formation. ${ }^{14,19}$

Saliva, a non invasive source, can be used to diagnose TMD. The group of subjects with stress and TMD showed higher level of salivary cortisol. Cortisol in saliva can be used for accurate prediction of stress and TMD. ${ }^{14}$ There were significant differences in the diurnal decline of salivary cortisol concentrations between individuals with and without sign and symtoms of TMD.

TMD patients are likely to presents higher salivary cortisol levels as a response to the stress of TMD pain. ${ }^{36}$ It has been reported that the group of participants with stress and TMD showed significant higher salivary cortisol levels $(177.8 \pm 12.24 \mathrm{ng} / \mathrm{mL})$ than the control group $(22.9 \pm 2.28 \mathrm{ng} / \mathrm{mL}) .{ }^{14}$ In addition higher cortisol value has been shown to be correlated with the Visual Analogue Scale (VAS) score. ${ }^{12}$

\section{Total Antioxidant Capacity (TAC)}

Oxidative changes seem to influence the pathogenesis of pain in TMD. ${ }^{15}$ Previous studies have confirmed that the reduction of TAC in patients with acute pain or inflammation. ${ }^{20-22}$ In TMD, trauma, mechanical stress, disc disorders and destructive changes can trigger the release of free radicals leading to osteoarthritis (OA) and oxidant/antioxidant imbalance. ${ }^{23}$ TMD patients with pain had significantly lower plasma TAC. This finding indicates that presence of inflammation and pain in the muscles or the TMJ results in higher production of free radicals in the site that initiates a cascade of inflammatory reactions. The result showed an inverse relationship between the plasma TAC and the severity of pain, the lower plasma concentration TAC, the pain more severe. Decreased TAC indicates oxidant/antioxidant imbalance due to pain mechanism. ${ }^{24}$ Oxidation of free radicals and activity of superoxide dismutase (SOD) in synovial fluid of patients with TMJ disorders has been shown to be correlated with the pathogenesis of TMD. ${ }^{25}$

\section{Dopamine}


Previous studies have suggested that dopamine neurotransmission can be altered at a central level in chronic pain conditions. ${ }^{26}$ Dopamine levels were higher in patients with myofacial pain TMD (M-TMD) than in healthy subjects; and correlated with pain intensity and perceived mental stress significantly. ${ }^{27}$ It has been reported that dopamine is significantly correlated with pain intensity in the masseter muscle, which suggests involvement of dopamine in pain modulation at the peripheral level. Patients with MTMD had higher levels of perceived mental stress than healthy controls. ${ }^{28}$ Mental stress correlated significantly with present pain intensity and dopamine in plasma. ${ }^{29}$ Peripheral dopamine may be involved in peripheral pain modulation indicates that peripheral dopamine could be implicated in the pathophysiology of other chronic pain conditions and M-TMD. ${ }^{26}$

\section{BIOMARKER IN INTERNAL DERANGEMENT}

The etiologies and pathogenesis of TMD are poorly understood so the diagnose and management of the disease are difficult. All treatments of TMD are palliative. Internal derangement is one of RDC/TMD first axis diagnostic group, it refers to a conditions in which the articular disc has become displaced from its original position. The displacement of the disc comprises two displacement: with reduction (with or without intermittent locking) and without reduction (with or without limited opening). ${ }^{6,30}$ Prevalence of internal derangement is $42 \%$ from 462 patients in Pavia, Italy. Although the prevalence is lower than myofascial pain or degenerative joint disease (arthralgia, OA and osteoarthrosis), the internal derangement has a stronger association with quality of life. ${ }^{31}$ The signs and symptoms of internal derangement are non specific and can be caused by multiple factors. ${ }^{32}$ The causes of pain in TMD patients are not clearly understood but the pain symptoms frequently arise in patients with internal derangement. ${ }^{33}$

\section{BIOMARKER IN OA}

Based on RDC/TMD, OA is included in degenerative joint disorders. Epidemiological studies estimate around 43 million affected patients in the United States. Epidemiological studies of the last decades tried to define risk factors such as age, genetic predisposition, obesity, joint congruency, increased mechanical stress and greater bone density. ${ }^{37}$ Degenerative diseases of the TMJ occur from the loss in equilibrium of anabolic and catabolic processes involving chondrocyte initiation, proliferation, differentiation, and matrix synthesis and degradation. ${ }^{38}$

Examination to determine temporomandibular joint abnormalities during this time using radiological examination. Radiographic signs of bony changes associated with TMJ OA include irregular and possibly thickened cortical outlines (sclerosis), erosions, osteophyte formation, subchondral cysts, flattening and narrowing of the joint space. ${ }^{39}$ CBCT images allow reliable detection and localization of bony changes, and increase the possibility for early detection of TMJ degenerative processes in asymptomatic patients. ${ }^{40}$

The sample used to detect biomarkers of TMJ OA are saliva, serum and blood. Synovial lavage is common sample for showing change of local biological mediator and predicting the status of diseases. Inflammatory mediators, MMPs, and aggrecanase are increased in patients with TMJ disorders. Expression of IL-8 and microvessel density are also increased in TMD patients. ${ }^{38}$ 
In the progression of TMJ OA, IL12, IL1 $\beta$, IL6, and TNF| | are increased in the synovial fluid. ${ }^{11,42}$ Monocyte chemoattractant protein (MCP)1 was highly upregulated in IL1| |-stimulated synoviocytes of the TMJ. MCP-1 plays an important role in recruiting mononuclear cells to inflamed synovial tissues. ${ }^{43}$. Increased expressions of IL1 $\beta$ and $\mathrm{TNF} \mid$ | were observed in the experimental chronic inflammation, suggesting that they can be one of the causes for the degenerative changes of TMJ, leading to deterioration of the TMJ's adaptive capability. ${ }^{44}$

\section{Conclusion}

Early diagnosis of TMD can be done by non-invasive methods through saliva, serum and blood. Cortisol, TAC and dopamine can be potential biomarkers for TMD.

\section{Reference}

1. Pawar R, Gulve N, Nehete A, Dhope S, Deore D, Chinglembi N. Examination of the Temporomandibular Joint- A Review. :7.

2. Østensjø V, Moen K, Storesund T, Rosén A. Prevalence of Painful Temporomandibular Disorders and Correlation to Lifestyle Factors among Adolescents in Norway. Pain Research and Management. 2017;2017:1-10.

3. Coêlho TG da S, Caracas HCPM. Perception of the relationship between TMD and orthodontic treatment among orthodontists. Dental Press Journal of Orthodontics. 2015 Feb;20(1):45-51.

4. Bertoli FM de P, Bruzamolin CD, Pizzatto E, Losso EM, Brancher JA, de Souza JF. Prevalence of diagnosed temporomandibular disorders: A cross-sectional study in Brazilian adolescents. Milgrom PM, editor. PLOS ONE. 2018 Feb 8;13(2):e0192254.

5. Berge T, Schjødt B, Bell RF, Johansson A, Paulsberg A-G, Geitung J-T, et al. Assessment of patients with severe temporomandibular disorder in Norway - a multidisciplinary approach. :8.

6. Schiffman E, Ohrbach R, Truelove E, Look J, Anderson G, Goulet J-P, et al. Diagnostic Criteria for Temporomandibular Disorders (DC/TMD) for Clinical and Research Applications: Recommendations of the International RDC/TMD Consortium Network* and Orofacial Pain Special Interest Group $\dagger$. Journal of Oral \& Facial Pain and Headache. 2014 Jan;28(1):6-27.

7. Roda RP, Bagán JV, Fernández JMD, Bazán SH, Soriano YJ. Review of temporomandibular joint pathology. Part I: Classification, epidemiology and risk factors. Med Oral Patol Oral Cir Bucal. :7.

8. Witulski S, Vogl TJ, Rehart S, Ottl P. Evaluation of the TMJ by means of Clinical TMD Examination and MRI Diagnostics in Patients with Rheumatoid Arthritis. BioMed Research International. 2014;2014:1-9.

9. Smith SB, Maixner DW, Greenspan JD, Dubner R, Fillingim RB, Ohrbach R, et al. Potential Genetic Risk Factors for Chronic TMD: Genetic Associations from the OPPERA Case Control Study. The Journal of Pain. 2011 Nov;12(11):T92-101.

10. Kobayashi FY, GaviãO MBD, Marquezin MCS, Fonseca FLA, Montes ABM, Barbosa $\mathrm{T}$ de $\mathrm{S}$, et al. Salivary stress biomarkers and anxiety symptoms in children with and without temporomandibular disorders. Brazilian Oral Research [Internet]. 2017 Oct 9 [cited 2018 Sep 18];31(0). Available from: http://www.scielo.br/scielo.php?script=sci_arttext\&pid=S1806$83242017000100264 \& \operatorname{lng}=\mathrm{en} \& \operatorname{tn} \mathrm{ln}=\mathrm{en}$ 
11. Vernal R, Velásquez E, Gamonal J, Garcia-Sanz JA, Silva A, Sanz M. Expression of proinflammatory cytokines in osteoarthritis of the temporomandibular joint. Archives of Oral Biology. 2008 Oct;53(10):910-5.

12. Benedetta C. Salivary cortisol levels in women with muscular facial pain. :9.

13. Tumer MK, Yerliyurt K, Nursal AF, Karakus N, Tekcan A, Yigit S. Impact of glucocorticoid receptor gene Bcl-1 variant on temporomandibular disorders. Biomed Res. 2017;28(20):6.

14. Ali SQ, Hadi R. Assessment of Cortisol as Salivary Psychological Stress Marker in Relation to Temporomandibular Disorders among a Sample of Dental Students. Journal of Baghdad College of Dentistry. 2015;27(2):86-92.

15. de Almeida C, Amenábar JM. Changes in the salivary oxidative status in individuals with temporomandibular disorders and pain. Journal of Oral Biology and Craniofacial Research. 2016 Nov;6:S1-4.

16. MS Greenberg, Glick M. Burket's oral medicine diagnosis \& treatment. 10th ed. Hamilton; 2003.

17. De Leeuw R, Klasser G. Orofacial pain. Guidelines for assessment, diagnosis, and management. 5th ed. Chicago: Quintessence Publishing Co, Inc.; 2013.

18. Manfredini D, Lobbezoo F. Relationship between bruxism and temporomandibular disorders: a systematic review of literature from 1998 to 2008. Oral Surg Oral Med Oral Pathol Oral Radio Endod. 2010;109:26-50.

19. Hoehn K, Marieb E. Human Anatomy and Physiology. San Francisco: Benjamin Cummings; 2010.

20. Halliwell B, Gutteridge J. Free radicals in biology and medicine. 1st ed. Oxford University; 2007. 112-118 p.

21. Chi C, Shiesh S, Lin X. Total antioxidant capacity and malondialdehyde in acute abdominal pain. Am J Emerg Med. 2002 Mar;20(2):79-82.

22. Abu-Hilal M, McPhail M, Marchand L, Johnson C. Malondialdehyde and superoxide dismutase as potential markers of severity in acute pancreatitis. JOP. 2006 Mar 9;7(2):18592.

23. Wang X, Kou X, Mao J, Gan Y, Zhou Y. Sustained inflammation induces degeneration of the temporomandibular joint. J Dent Res. 2012 May;91(5):499-505.

24. Vakili V. Comparison of serum and salivary antioxidants in patients with temporomandibular joint disorders and healthy subjects. Journal of Dentistry. 12(4):8.

25. Cai H, Luo J, Long X, Xi L, Cheng Y. Free-radical oxidation and superoxide dismutase activity in synovial fluid of patients with temporomandibular disorders. $\mathrm{J}$ Orofac Pain. 2006;20(1):53-8.

26. Dawson A, Stensson N, Ghafouri B, Gerdle B, List T, Svensson P, et al. Dopamine in plasma - a biomarker for myofascial TMD pain? The Journal of Headache and Pain [Internet]. 2016 Dec [cited 2018 Oct 15];17(1). Available from: https://thejournalofheadacheandpain.biomedcentral.com/articles/10.1186/s10194016-0656-3

27. Wood P, Patterson J, Sunderland J. Reduced presynaptic dopamine activity in fibromyalgia syndrome demonstrated with positron emission tomography: a pilot study. J Pain. 2007;8(1):51-8.

28. Jasim H, Louca S, Christidis N. Salivary cortisol and psychological factors in women with chronic and acute oro-facial pain. J Oral Rehabil. 2014;41(2):122-32. 
29. Maixner W, Greenspan J, Dubner R. Potential autonomic risk factors for chronic TMD: descriptive data and empirically identified domains from the OPPERA casecontrol study. J Pain. 2011;12(11):75-91.

30. Young A. Internal derangements of the temporomandibular joint: A review of the anatomy, diagnosis, and management. The Journal of Indian Prosthodontic Society. 2015;15(1):2.

31. Manfredini D, Arveda N, Guarda-Nardini L, Segù M, Collesano V. Distribution of diagnoses in a population of patients with temporomandibular disorders. Oral Surgery, Oral Medicine, Oral Pathology and Oral Radiology. 2012 Nov;114(5):e3541.

32. Tatli U, Machon V. Internal Derangements of the Temporomandibular Joint: Diagnosis and Management. In: Emes Y, Aybar B, Dergin G, editors. Temporomandibular Joint Pathology - Current Approaches and Understanding [Internet]. InTech; 2018 [cited 2018 Oct 14]. Available from: http://www.intechopen.com/books/temporomandibular-joint-pathology-currentapproaches-and-understanding/internal-derangements-of-the-temporomandibularjoint-diagnosis-and-management

33. Koh K-J, Park H-N, Kim K-A. Internal derangement as a predictor of provoked pain on mouth opening: A magnetic resonance imaging study. Imaging Science in Dentistry. 2017;47(4):219.

34. Shafer DM, Assael L, White B, Rossomando F. Tumor Necrosis Factor-a as a Biochemical Marker of Pain and Outcome in Temporomandibular Joints With Internal Derangements. :6.

35. Emshoff R, Puffer P, Rudisch A, Gaßner R. Temporomandibular joint pain: Relationship to internal derangement type, osteoarthrosis, and synovial fluid mediator level of tumor necrosis factor- $\alpha$. Oral Surgery, Oral Medicine, Oral Pathology, Oral Radiology, and Endodontology. 2000 Oct;90(4):442-9.

36. Barbosa T, Castelo P, Leme M, Gavião M. Associations between oral health-related quality of life and emotional statuses in children and preadolescents: Oral healthrelated quality of life and emotional statuses. Oral Diseases. 2012 Oct;18(7):63947.

37. Egloff C, Hügle T, Valderrabano V. Biomechanics and pathomechanisms of osteoarthritis. Swiss Medical Weekly [Internet]. 2012 Jul 19 [cited 2018 Oct 14]; Available from: http://doi.emh.ch/smw.2012.13583

38. Wadhwa S. TMJ Disorders: Future Innovations in Diagnostics and Therapeutics. 2008;24.

39. Ahmad M, Hollender L, Anderson Q, Kartha K, Ohrbach R, Truelove EL, et al. Research diagnostic criteria for temporomandibular disorders (RDC/TMD): development of image analysis criteria and examiner reliability for image analysis. Oral Surgery, Oral Medicine, Oral Pathology, Oral Radiology, and Endodontology. 2009 Jun;107(6):844-60.

40. Walker DG. A 3D Imaging and Biological Marker Analysis of TMJ OA: A new Modeling Technique. :61.

41. Freitas de Souza R, Lovato da Silva CH, Nasser M, Fedorowicz Z. Interventions for the management of temporomandibular joint osteoarthritis. In: The Cochrane Collaboration, editor. Cochrane Database of Systematic Reviews [Internet]. Chichester, UK: John Wiley \& Sons, Ltd; 2008 [cited 2018 Oct 15]. Available from: http://doi.wiley.com/10.1002/14651858.CD007261 
42. Cevidanes LHS, Walker D, Schilling J, Sugai J, Giannobile W, Paniagua B, et al. 3D osteoarthritic changes in TMJ condylar morphology correlates with specific systemic and local biomarkers of disease. Osteoarthritis and Cartilage. 2014 Oct;22(10):1657-67.

43. Ogura N, Satoh K, Akutsu M, Tobe M, Kuyama K, Kuboyama N, et al. MCP-1 Production in Temporomandibular Joint Inflammation. J Dent Res. 2010 Oct $1 ; 89(10): 1117-22$.

44. Wang XD, Zhang JN, Gan YH, Zhou YH. Current Understanding of Pathogenesis and Treatment of TMJ Osteoarthritis. Journal of Dental Research. 2015 May;94(5):666-73.

45. Campos MIG, Campos PSF, Line SRP. Inflammatory cytokines activity in temporomandibular joint disorders: a review of literature. :9.

46. Kotake S, Sato K, Kim K, Takahashi N, Udagawa N, Nakamura I. Interleukin-6 and soluble interleukin-6 receptors in the synovial fluids from rheumatoid arthritis patients are responsible for osteoclast-like cell formation. J Bone Miner Res. 1996;11:88-95.

47. Steiner G, Studnicka-Benke A, Witzmann G, Hofler E, Smolen J. Soluble receptors for tumor necrosis factor and interleukin2 in serum and synovial fluid of patients with rheumatoid arthritis, reactive arthritis and osteoarthritis. J Rheumatol. 1995;22:406-12.

48. Kubota E, Imamura H, Kubota T, Shibata T, Murakami K. Interleukin 1 beta and stromelysin (MMP3) activity of synovial fluid as possible markers of osteoarthritis in the temporomandibular joint. J Oral Maxillofac Surg. 1997;55:20-8.

49. Kubota E, Kubota T, Matsumoto J, Shibata T, Murakami K-I. Synovial fluid cytokines and proteinases as markers of temporomandibular joint disease. Journal of Oral and Maxillofacial Surgery. 1998 Feb;56(2):192-8.

50. Ijima Y, Kobayashi M, Kubota E. Role of interleukin-1 in induction of matrix metalloproteinases synthesized by rat temporomandibular joint chondrocytes and disc cells. Eur J Oral Sci. 2001;109:50-9.

51. Puzas J, Landeau J, Tallents R, Albright J, Schwarz E, Landesberg R. Degradative pathways in tissues of the temporomandibular joint. Use of in vitro and in vivo models to characterize matrix metalloproteinase and cytokine activity. Cells Tissues Organs. 2001;169:248-56. 